\title{
Evaluation of Urban Architecture Design and Construction on Environmental Pollution under the Visual Threshold of Green Development
}

\author{
Xin Fu and Shisheng Lyu† \\ College of Art and Design, Wuhan Textile University, Wuhan 430070, China \\ †Corresponding author: Shisheng Lyu: lvgege007@163.com
}

Nat. Env. \& Poll. Tech. Website: www.neptjournal.com

Received: 27-02-2021

Revised: 13-04-2021

Accepted: 25-04-2021

Key Words:

Green development Urban building construction

Architectural design

Environmental protection

Evaluation model

\begin{abstract}
The obvious manifestation of urban development is the integrated development of urban architectural design and construction. The environmental protection of green building design and construction has become an important link that cannot be ignored in the process of urban green development. Green building materials, green design, and other environmentally friendly building programs are the subjective manifestations of the implementation of the green development concept. However, the degree of environmental protection is still a black box that needs to be explored urgently. To explore the environmental pollution caused by urban architectural design and construction in the process of urban development, an evaluation model of urban architectural design and construction on environmental pollution was constructed. The first-level evaluation indicators include ecology, natural, and social environments, of which the corresponding secondary indicators mainly include noise, water, and air pollution and other 12 indicators. The weights of the evaluation indicators at all levels were calculated using the expert evaluation method, and the weighting method was then combined to evaluate the pollution. Results show that the main sources of environmental pollution caused by urban building design and construction are solid waste pollution and traffic congestion rather than traditional noise and air pollution. Noise and air pollution are effectively controlled in the construction process. The evaluation system provides further directions for improvement in the prevention and control of environmental pollution in building construction and provides a reference for effective improvement of environmental governance.
\end{abstract}

\section{INTRODUCTION}

Adhering to green development is a profound revolution in the outlook on development. Extraordinary measures must be taken in terms of transforming the economic development model, comprehensive management of environmental pollution, natural ecological protection and restoration, resource conservation and intensive utilization, and perfecting the ecological civilization system. Ecological environmental protection must also be performed in all directions, all regions, and the whole process (Liu 2020). The green development concept guides the construction of ecological civilization, promotes social progress, and improves the quality of urban life. The obvious manifestation of urban development is the replacement of urban planning and urban buildings. The construction of urban buildings caused by the building replacement process will inevitably cause "non-green" phenomena, such as the occupation of space, noise pollution, road closures, and inhalable particle pollution. Some studies have indicated that urban construction pollution has become a short-term key consideration factor for migrants in choosing a place to live.
Solving the problem of environmental pollution caused by urban construction has become an effective way to stimulate population distribution in urban areas.

Urban construction is an urban planning activity that meets the needs of urban development, increases the occupancy rate of urban areas, and improves the appearance of cities. Urban development urgently needs the participation of urban construction (Teng 2020). The construction process requires a large amount of water supply to maintain the normal operation of the construction. At the same time, a large amount of wastewater and sewage is discharged, which causes a certain amount of water pollution to the surrounding environment.

In addition, modern building construction uses mechanical operations instead of traditional labour, which improves the efficiency of construction but causes serious mechanical noise pollution. As a result, it has a great impact on the daily life and health of surrounding residents. Building construction requires granular materials such as cement and sand. When the particle diameter is less than $10 \mu \mathrm{m}$, polluting inhalable particles will be formed in the air, posing a threat 
to the health of residents. When a large number of inhalable particles accumulate, the increase in concentration will reduce the visibility of the air and cause serious pollution to the atmosphere.

Moreover, building construction is sometimes conducted at night and requires a considerable amount of lighting to maintain normal operations. The resulting light pollution affects the normal rest of the surrounding residents and reduces the quality of life and wellbeing of surrounding residents (Li et al. 2015). Furthermore, if the solid waste generated by the building (e.g., residues from the demolition of old buildings, the abandonment of excess materials during the construction process, and the muck produced by underground excavation during the construction process) is discarded without treatment, it will not only cause a waste of resources but also cause great pollution to the environment (Roberto et al. 2012).

Therefore, urban construction under the background of green development must not only ensure the normalization of its development but also minimize the environmental pollution that it causes. How to evaluate the environmental pollution caused by urban construction is conducive to controlling different sources of pollution during the construction process, taking targeted measures to effectively reduce construction pollution, realizing urban green construction, and promoting urban green development.

\section{PAST WORK CARRIED OUT}

With the continuous advancement of the green development process, the concept of green sustainability has penetrated all areas of social life. The most intuitive manifestation of the green development of urban construction is the application of green building materials and the implementation of green building design concepts (Wang et al. 2020). The core purpose of urban green buildings is to reduce environmental pollution caused by the construction process. Based on existing research, urban construction pollution is mainly reflected in water, air, noise, light, and solid waste pollution.

\section{Water Pollution Caused by Urban Building Construction}

Water pollution refers to the deterioration of the physical, chemical, and biological characteristics of the water body due to the discharge of pollutants. As a result, it will destroy the original ecosystem and water body functions, exceed the self-purification capacity of the waterbody and prevent the water from being effectively used (Cheng et al. 2021). It even endangers the health of animals and plants. Water pollution in the process of building construction mainly comes from rainwater and sewage (Sandeep et al. 2019).

Sewage is divided into domestic water for on-site staff and construction water. Rainwater and sewage diversion technology is used to realize the recycling of rainwater and sewage. The rainwater flows directly into the municipal rainwater pipeline through the drainage ditch. For the domestic sewage generated by the on-site construction personnel, in addition to the centralized treatment, the site toilet should be equipped with septic tanks or use mobile public toilets to reduce sewage discharge. The main sources of construction water are: (1) mechanical operation and cleaning; (2) sewage discharge from construction operations; (3) drainage and precipitation of foundation pits; and (4) sewage and wastewater generated by exposed building materials and toxic and harmful substances after being washed by rain $(\mathrm{Lu}$ et al. 2021).

For this type of construction water, after using the sedimentation tank to settle the debris, most of the wastewater can be recycled and used for sprinkling on construction sites to reduce dust. A small part of the more polluted sewage and wastewater is discharged into the municipal pipeline after being treated by the biological tank (Wang 2020). Construction sewage containing special substances, such as chemicals and oil materials containing toxic and hazardous substances, should be treated by an oil-water separator and discharged reasonably.

\section{Air Pollution Caused by Urban Building Construction}

Air pollution is general pollution caused by construction projects. Building dust and exhaust gas seriously affect urban air quality, such as urban smog, which seriously affects the human respiratory system and restricts urban development. At present, the control measures for air pollution mainly focus on preventive measures, supplemented by control measures (Huang et al. 2007).

Air pollution during construction is mainly dust and waste gas. Fugitive dust includes that generated during the transportation and loading and unloading of materials, the dust formed after mud accumulation and drying, and the large amount of fugitive dust generated during the demolition of the original buildings on the site. The exhaust gas mainly comes from the exhaust emissions of machinery and automobiles during the construction phase and the toxic and harmful gases released after the use of volatile materials (Haron et al. 2009). Moreover, during the implementation of construction projects, some paints and other materials used generally contain formaldehyde and other easily volatile harmful components, which cause the air to be polluted by harmful gases. 


\section{Noise Pollution Caused by Urban Building Construction}

Construction noise refers to the environmental noise generated on construction sites, which is mainly generated by equipment operation, material processing, transportation, loading and unloading, earth and stone construction, piling, and structural construction (Zheng et al. 2015). The noise pollution caused by the construction of a large number of buildings considerably affects the people living nearby. Construction noise must be strictly managed and controlled from the three links of noise sources, noise transmission channels, and noise receivers.

Regarding noise sources, machinery should be upgraded, optimized, and maintained. Moreover, the noise interference caused by night construction should be minimized, noiseprone mechanical equipment should be kept away from the crowd as much as possible, and the construction schedule should be reasonably arranged to minimize noise pollution. The construction should also follow the relevant standards for noise control, following the Environmental Noise Emission Standards at the Boundary of Construction Sites formulated by the Ministry of Ecology and Environment. During the construction process of a building project, the specified range of noise caused by construction should be less than 70 $\mathrm{dB}$ during daytime construction and less than $55 \mathrm{~dB}$ during night construction.

\section{Light Pollution and Waste Pollution Caused by Urban Building Construction}

Light pollution is also a part of environmental pollution. To complete the construction schedule or part of the project needs to be completed at night; lighting must be used to ensure the smooth progress of the construction. This pollution will affect the quality of people's rest at night, and in severe cases will affect people's physical and mental health. In this regard, the control of light pollution is also in need of improvement in construction projects (Bagula et al. 2015.).

The solid waste generated at construction sites is mainly domestic waste and industrial solid waste, which refer to construction waste and waste residues, such as broken bricks, mortar, concrete, wood, and steel. At this stage, an increasing amount of construction waste is generated during construction. Related data show that construction waste accounts for $30 \%-40 \%$ of urban waste in our country, and construction waste is prone to secondary pollution, such as dust and wastewater during transportation (Frauke 2016). This phenomenon causes great harm to the ecological environment while endangering human health.

In the initial stage of construction, the relevant construction unit should strictly perform garbage classification management for domestic garbage and clean up in time to avoid secondary pollution caused by random disposal of garbage. For industrial solid waste, classification and reduction treatment should be implemented (Wang et al. 2018). The recycled materials should be recovered and processed in time. Some of the materials that cannot be recycled should enter the social recycling system to achieve sustainable development under the circular economy. The other part should be processed by physical methods (e.g., crushing and landfill after pressure storage) and chemical methods (e.g., high-temperature decomposition and oxidation) to reduce the accumulation of garbage.

\section{MATERIALS AND METHODS}

\section{Evaluation Indicators}

The pollution caused by urban construction causes considerable damage to the environment. To effectively control the adverse effect of construction on the environment, the multi-party pollution caused by urban construction must be rationalized, and targeted treatment must be performed to minimize the index of environmental pollution. While ensuring people's quality of life, it also allows the green and sustainable development of a country's construction industry.

Aiming at different aspects of environmental pollution, Wang et al. (2020) calculated the improvement effect of green energy-saving building construction on environmental pollution through the weighting index. Then, they constructed an analysis model and realized the improvement effect analysis of green energy-saving building construction. Cheng et al. (2021) proposed environmental protection in terms of policy factors, planning factors, technical applications by using the method of the green construction evaluation of prefabricated building based on the G1-entropy-independence weight method, and probability language close to entropy to analyze the weight of 21 pollution indicators. Finally, they provided scientific advice for the selection of the project plan.

Based on a large number of literature searches, the environmental pollution caused by urban construction involves water, air, solid waste, noise, and light pollution; urban landscape; and population health. Further classification of the pollution indicators can determine the environmental pollution, involving the ecological, natural, and social environments. This study summarizes and sorts out the evaluation indicators of the impact of urban construction on the environment, as shown in Fig. 1.

\section{Evaluation Model}

The entropy weight method is an objective weighting method to determine the index weight coefficient according to the 


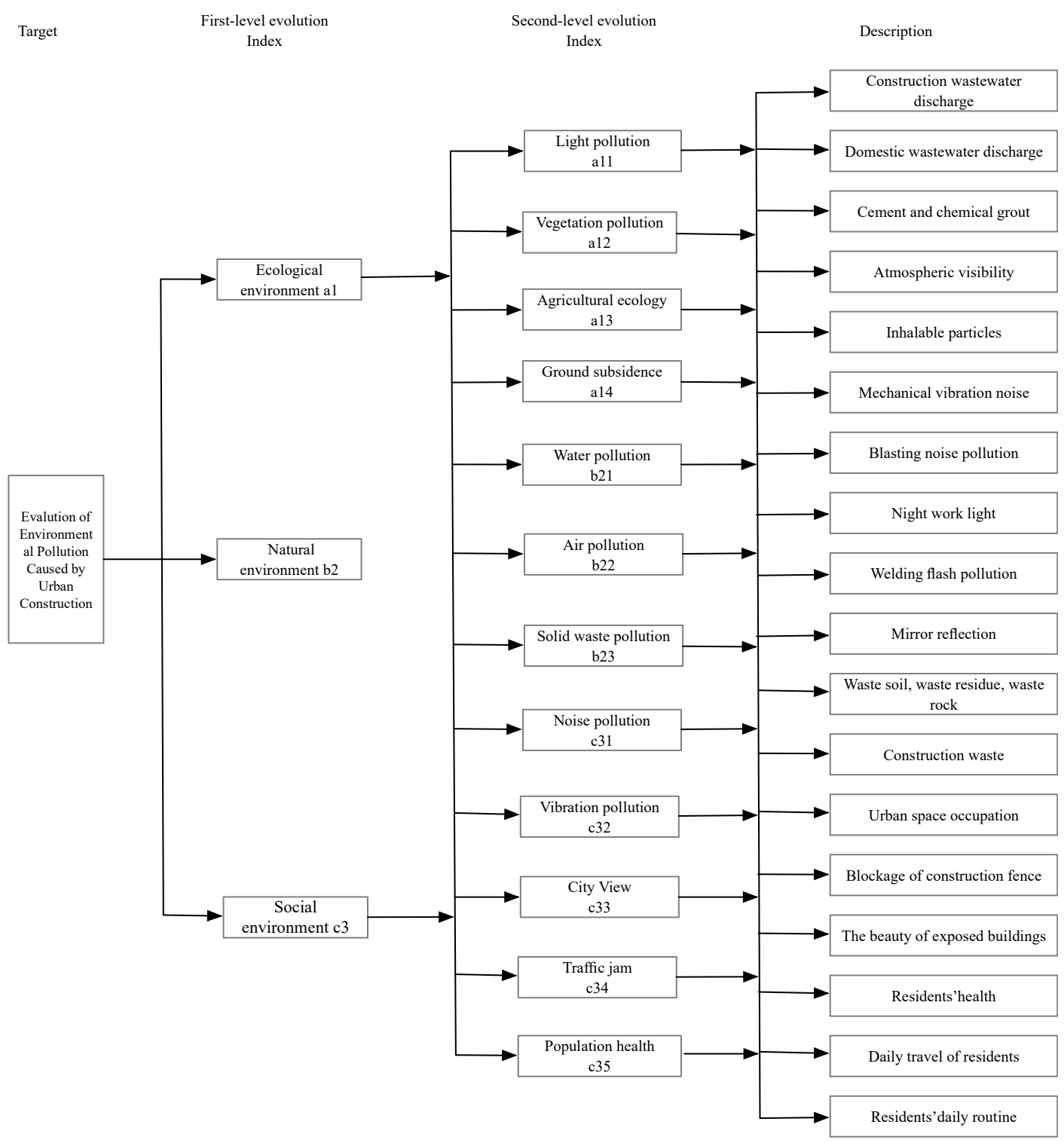

Fig. 1: Evaluation Index System for environmental pollution caused by urban construction.

amount of sample information contained in the evaluation index. Entropy is a measure of the disorder degree of index information. The smaller the entropy value of an index is, the greater the variation degree of its index value is, and the more information it can provide (Smart 2015). Therefore, the greater the role of this index in the comprehensive evaluation, the greater its weight value should be. The weight calculation steps of the entropy weight method are as follows:

1. The original data is standardized, and then the normalized standard matrix is constructed.

$$
A=\left(a_{i j}\right)_{m \times n}=\left[\begin{array}{ccc}
A_{11} & \cdots & A_{n 1} \\
\vdots & A_{i j} & \vdots \\
A_{m 1} & \cdots & A_{m n}
\end{array}\right]
$$

2. According to the definition of entropy, the entropy value of the $j$-th index is calculated as follows:

$$
Y_{j}=-k \sum_{i=1}^{m} p_{i j} \ln p_{i j}
$$

Among them: 


$$
\left\{\begin{array}{l}
k=(\ln m)^{-1} \\
p_{i j}=\frac{r_{i j}}{\sum_{i=1}^{m} r_{i j}}
\end{array}\right.
$$

By selecting the size of the constant $k$, the entropy value is always controlled within the interval of $[0,1]$.

3. Calculate the difference of the $j$ th index.

$$
c_{j}=1-Y_{j}
$$

Calculate the weight value of the $j$ th index:

$$
w_{j}^{\prime}=\frac{c_{j}}{\sum_{j=1}^{n} c_{j}}, j=1,2, \cdots, m
$$

Among them, the difference coefficient A represents the importance of this index in the whole evaluation system. The greater the value of $\mathrm{A}$ is, the greater the importance of this index in the overall evaluation system, and the greater the weight value of the corresponding index $\mathrm{B}$ is.

\section{RESULTS ANALYSIS AND DISCUSSION}

\section{Case Description}

A residential project of Wanke in Wuhan of China covers an area of $59,917 \mathrm{~m}^{2}$ and a building area of $386,968.7 \mathrm{~m}^{2}$, with a total of 12 buildings. The project has a large construction volume and a long construction period. The index system and evaluation model constructed in this study will be used to perform an environmental pollution assessment on this project.

Six qualified experts from the engineering construction environmental pollution control industry were invited to score the pollution of the project. To ensure the effectiveness and independence of the scoring, high industry requirements were observed for the qualification review of experts. Experts should have been engaged in the industry for a long time with rich field experience and have unique insights into management. Based on construction evaluation standards and environmental pollution, they would quantitatively evaluate the indicators constructed in Fig. 1 and score them on a fivepoint system. The evaluation results of the various indicators on environmental pollution are shown in Table 1.

\section{Weight Analysis}

Based on the evaluation results of environmental pollution by various indicators, the entropy weight method is used to process the entropy value and entropy weight of the standardized matrix. Formulas (4) and (5) are used to obtain the entropy weight of the environmental pollution indicators, as shown in Table 3.

The results of entropy weighting of the environmental pollution indicators for urban building design and construc-

Table 1: Evaluation results of primary indicators.

\begin{tabular}{|c|c|c|c|c|c|c|}
\hline \multirow[t]{2}{*}{ Index } & \multicolumn{6}{|l|}{ Expert } \\
\hline & Expert 1 & Expert 2 & Expert 3 & Expert 4 & Expert 5 & Expert 6 \\
\hline a11 & 3.5 & 3.5 & 4.5 & 2 & 2.5 & 3 \\
\hline a12 & 3 & 3.5 & 2.5 & 3 & 3.5 & 3.5 \\
\hline a13 & 3.5 & 3 & 2.5 & 3 & 3 & 3 \\
\hline a14 & 3 & 2.5 & 2.5 & 3.5 & 3 & 2.5 \\
\hline b21 & 3 & 3 & 2.5 & 3 & 2.5 & 3 \\
\hline b22 & 2 & 2.5 & 2.5 & 3 & 2.5 & 3 \\
\hline b23 & 2.5 & 1.5 & 2.5 & 3.5 & 3 & 3 \\
\hline c31 & 3 & 3 & 3.5 & 3 & 3 & 2.5 \\
\hline c32 & 3 & 3.5 & 3 & 2.5 & 2.5 & 3 \\
\hline c33 & 3.5 & 3 & 3 & 3 & 3.5 & 2.5 \\
\hline c34 & 3 & 3 & 3.5 & 3 & 3 & 2.5 \\
\hline c35 & 3 & 3 & 3 & 3.5 & 3 & 3 \\
\hline
\end{tabular}

\begin{tabular}{|lllllll|}
\hline Index & Expert & & & & \\
\cline { 2 - 6 } & Expert 1 & Expert 2 & Expert 3 & Expert 4 & Expert 5 & Expert 6 \\
\hline Ecological environment a1 & 3 & 2.5 & 3.5 & 2 & 3 \\
Natural environment b2 & 3 & 3.5 & 3.5 & 3 & 3.5 & 3.5 \\
Social environment c3 & 3.5 & 4 & 3.5 & 4 & 4 \\
\hline
\end{tabular}

Table 2: Evaluation results of secondary indicators. 
Table 3: Entropy weight of environmental pollution indicators.

\begin{tabular}{|c|c|c|c|c|}
\hline Target layer & First-level index & Weight & Second-level index & Weight \\
\hline \multirow{12}{*}{$\begin{array}{l}\text { Evaluation of Environmental Pollution Caused } \\
\text { by Urban Construction }\end{array}$} & \multirow[t]{4}{*}{ Ecological environment a1 } & \multirow[t]{4}{*}{0.222} & a11 & 0.243 \\
\hline & & & a12 & 0.098 \\
\hline & & & a13 & 0.391 \\
\hline & & & a14 & 0.068 \\
\hline & \multirow[t]{3}{*}{ Natural environment b2 } & \multirow[t]{3}{*}{0.172} & $\mathrm{~b} 21$ & 0.222 \\
\hline & & & b22 & 0.229 \\
\hline & & & b23 & 0.460 \\
\hline & \multirow[t]{5}{*}{ Social environment $\mathrm{c} 3$} & \multirow[t]{5}{*}{0.101} & $\mathrm{c} 31$ & 0.089 \\
\hline & & & $\mathrm{c} 32$ & 0.203 \\
\hline & & & $\mathrm{c} 33$ & 0.371 \\
\hline & & & c34 & 0.426 \\
\hline & & & $\mathrm{c} 35$ & 0.127 \\
\hline
\end{tabular}

tion show that the environmental pollution indicators of this Wanke residential project in Wuhan are ranked as solid waste pollution, traffic congestion, agricultural ecological pollution, urban landscape pollution, light pollution, air pollution, water pollution, and vibration, as well as pollution, population health, vegetation pollution, noise pollution, land subsidence. The result shows that the most significant environmental pollution caused by the design and construction of buildings in the city centre is solid waste pollution (0.460).

The above finding is due to the replacement of urban buildings requiring the re-planning and demolition of the building design. The demolition of old buildings is prone to generate a large amount of solid waste pollution. The treatment of solid waste pollution cannot be treated like a landfill in a large rural area. Solid waste will be transported after crushing, which leads to the accumulation of solid waste pollution.

Before the project starts, preparations for solid waste treatment should be made, and solid waste must be eliminated to the maximum extent. In the pollution in architectural design and construction, the widely criticized weight indicators of air, vibration, and noise pollution rank sixth, eighth, and eleventh, respectively. This result shows that in today's urban architectural design and construction, air, vibration, and noise pollution are all well prevented and controlled. Land subsidence causes the least pollution, with a weight of only 0.068 . Thus, urban construction is the most serious problem for people's daily travel. Given the strict control of underground space in urban planning and design, the ground subsidence caused by construction has the smallest impact.

The results indicate that noise and air pollution have been effectively controlled during the construction of urban buildings. Urban construction is also responding to green development, and rational architectural design is a limited way to effectively reduce traditional pollution. The entropy method is used to evaluate the environmental pollution of urban buildings and constructions, which can be a positive test of the existing prevention and control work when it can effectively detect pollution indicators.

The weight of the primary indicator is obtained based on the data of the entropy weight of the secondary index. The data show that the pollution of the primary indicator of environmental pollution caused by urban building design and construction is the ecological environment pollution (0.222), which exceeds the other two indicators, followed by natural environmental pollution and finally social-environmental pollution. As the direct pollution object of urban architectural design and construction, ecological environmental pollution is relatively a concern. The reason is that with the development of the city, the green environment inside the city is destroyed, and the ecological pollution inside the city is aggravated ${ }^{15}$. The continuous expansion of the city has also caused great damage to the suburban environment around the city, and the external ecological pollution of the city has also increased. How to solve the problems of urban expansion and ecological environment protection has become an important issue that the government needs to consider. Second is the pollution of the natural environment. With the destruction of the ecological environment, the pollution of the natural environment also increases. The lower weight of the social environment indicates that social environmental damage caused by urban architectural design and construction is relatively small, and the project can improve pollution prevention and control for this matter. 


\section{Assessment of Environmental Pollution}

The combination weight method to determine the emergency capability index score is similar to the entropy weight method. All indicators of the community project in Wanke are calculated by $W \times R=R_{\text {line }}$, and the final specific scores of each indicator are obtained from $R_{\text {score }}=R_{\text {line }} \times[100,80,60,40,20]^{T}$. The strongest, stronger, general, weaker, and weak environmental impact is 100 $80,80-60,60-40,40-20$, and 20-0 points, respectively. The entropy weight of the environmental pollution indicators is combined. The specific scores of each indicator are [78.5, 52.1, 86.2, 43.2, 75.8, 76.2, 93.1, 48.6, 71.6, 83.7, $91.0,68.5]$. Further calculation of the project based on the indicator weight shows that the score of the environmental pollution impact assessment is 72.38 points, indicating that the project has a strong impact on environmental pollution. The evaluation results indicate that during the construction of the community project in Wanke, attention should be paid to the prevention, control, and monitoring of various pollution indicators to reduce environmental pollution and achieve green design and construction.

\section{CONCLUSION}

Aiming at the environmental pollution caused by urban construction, an environmental evaluation index system was constructed and the entropy method was used to evaluate $t$ the urban environmental pollution caused by the construction of a residential project in Wanke in Wuhan of China. The conclusions are drawn as follows.

1. The evaluation of environmental pollution in urban architectural design and construction includes three aspects: ecological environment, natural environment and social environment.

2. Taking a residential project in Wanke as an example, the evaluation results show that the environmental pollution caused by the construction of the project is mainly reflected in solid waste pollution, and the treatment of solid waste can be controlled to a certain extent through effective recycling. Conclusions indicate the feasibility of using the entropy weight method to evaluate the environmental pollution of urban construction design and construction.
This study solves the main aspects of pollution caused by the construction of this residential area in Wuhan. It can also be compared to other areas to uncover the black box of environmental pollution caused by urban construction, which will help promote the green and harmonious development of society.

\section{REFERENCES}

Bagula, A., Castelli, L. and Zennaro, M. 2015. On the design of smart parking networks in the smart cities: An optimal sensor placement model. Sensors, 15(7): 168-173.

Cheng, H., Lu, Y. H. and Liu, S. F. 2021. Green construction evaluation of prefabricated building based on g1-entropy-independence weight method. Mathematical Practice and Theory, 4(51): 75-87.

Frauke, B. 2016. Why cycling matters for smart cities, internet of bicycles for intelligent transport. Journal of Transport Geography, 56(3): 125-136.

Haron, Z., Yahya, K. and Mohamad, M.I. 2009. Probability approach for prediction of construction site noise. Journal of Asian Architecture and Building Engineering, 8(2): 571-577.

Huang, Y.H., Tian, G., Qin, J.P., Li, G. and Yan, B.L. 2007. Research on the characteristics of dust pollution in different construction stages. Environmental Science, (12): 2885-2888.

Li, M., Wei, Y. W. and Wang, Y. Q. 2015. Analysis of solid waste treatment and reuse technology on construction site. Earth, 12(7): 296-296.

Liu, X. 2020. Application of building construction emission reduction technology in environmental pollution control. Technical Analysis. 4(12): 45-46.

Lu, L. and Liu, C. Y. 2021. Research on airport comprehensive evaluation model based on entropy weight method. Aviation Computing Technology, 51(1): 64-66.

Roberto, P. and Esther, R. 2012. Development of environmental quality indexes based on fuzzy logic. A case study. Ecological Indicators, 23(3): 32-41.

Sandeep, B. and Geetha, G. 2019. Advanced evaluation methodology for water quality assessment using artificial neural network approach. Water Resources Management, 33(9): 129-141.

Smart, C. 2015. A conjuncture of four forces. Cities, 47(8): 95-106.

Teng, F.X. 2020. Research on green construction management of engineering buildings. Green Environmental Protection Building Materials, 7(26): 56-58.

Wang, Y., Wei, J.S., Li, X.T., Bai, Y. and Wen, X.C.Wang, Z. M. 2020. Application of ecological environment protection concept in residential building design. Low Carbon World, 209(11): 107-108.

Wang, W. and Sun, X. B. 2020. Analysis and research on the improvement effect of green energy-saving building construction on environmental pollution. Environmental Science and Management, 5(45): 164-168.

Zheng, R., Yao, C. W., Jin, H., Zhu, L., Zhang, Q. and Deng, W. 2015. Parallel key frame extraction for surveillance video service in a smart city. PloS One, 10(8): 13-18. 